\title{
A Faculdade Direito de São Paulo na Cultura Brasileira.
}

\author{
Miguel Reale \\ Professor Catedrático de Filosofia do Direito da Fa- \\ culdade de Direito da Universidade de São Paulo.
}

"Não podia ser senão assim. Não podia ser de outra forma. Esta noite só podia começar pela poesia, porque a poesia sempre esteve presente na história da Faculdade de Direito de São Paulo.

Poesia significa instauração criadora, penetração nas raízes do ser, porque é o mito que se faz palavra. E é palavra que se faz mito. Identidade absoluta entre a idéia e o sentimento, a poesia inspiradora e criadora figura no pórtico desta Casa com os nomes de Álvares de Azevedo, Castro Alves e Fagundes Varela, de tal modo que não se sabe se se entra nesta Faculdade para estudar Direito ou para realizar obra de arte, para fazer poesia. Poesia da mocidade que muitas vezes ensina mais do que a Cátedra; poesia desveladora que põe em dificuldade inmensa quem vos fala, dado o vulto das realizações históricas que compõem a memória cultural da nossa Academia.

\footnotetext{
*. Discurso proferido na Sessão Solene da Congregação, realizada no salão nobre a 11 de agosto de 1976, inaugaurando os festejos do Sesquicentenárlo da Fundaçáo dos Cursos Jurídicos no Brasil, e reconstituído pelo autor, à vista de gravação.
} 
Andou bem a Congregação dos Professores, em cujo nome estou falando neste instante, andou bem a Congregação ao destinar um ano todo às comemorações do sesquicennário da Lei de 11 de Agosto de 1827, dando início ao Ano Nacional do Direito, que começa hoje, só podendo começar com consciência histórica e com consciência crítica.

Não venho aqui para fazer o panegírico de nossa Faculdade, muito embora seja impossível falar dela sem que o coração bata de maneira mais apressada, mas venho para dizer o que representou e o que representa a Faculdade de Direito na cultura brasileira e, especialmente, na civilização de São Paulo.

11 de agosto de 1827 não foi uma conquista fácil, mas, ao contrário, o resultado de muitos contrastes e posições.

Quando, na Assembléia Constituinte de 1823, José Feliciano Fernandes Pinheiro, depois Visconde de São Leopoldo, propôs que se criasse a Faculdade de Direito em São Paulo, suscitou violenta oposição. Que é que se argüiu naquela éploca? E indispensável meditarmos sobre as críticas e o sentido final de uma diretriz fadada a exercer tão poderosa influência política e pedagógica em nosso País.

Dizia-se que São Paulo era pobre demais para receber uma Faculdade de Direito. Eis a primeira surpresa. A megalópolis de hoje, esta cidade que a todos assusta por seu vertiginoso crescimento, era apontada, nos primórdios da nossa Independência, como uma pobre Vila, onde os estudantes não teriam sequer lugar onde morar. - "Sessenta estudantes não terão onde passar a noite" - proclamava um dos deputados da Assembléia Constituinte.

Um outro acrescentava que em São Paulo, - que se tornou a cidade das mil línguas, nesta Torre de Babel em sentido inverso, que encontra na linguagem do trabalho o ponto de referência de todas as línguas do mundo, - só se falava um 
pobre dialeto caboclo, capaz de corromper a mocidade. Terra sem morada, pobreza de morar que é das mais tristes formas de pobrezas; povo sem linguagem, carência de expressão, que é a outra forma opressiva de pobreza; mas, debaixo dessas cinzas, mantinha-se viva a antiga força, o mesmo sentido de audácia e de realização que distinguira os bandeirantes e pulsava ainda no coração dos Andrada e de Feijó.

Valores há, e são os valores espirituais, que momentâneas deficiências de ordem material não logram destruir. Em nossos dias, temos o exemplo impressionante de nações que, destroçadas pela guerra, ressurgiram em poucos anos, graças ao poder demiurgo da inteligência e ao patrimônio da ciểncia, o único que não se exaure, pela força do amor às coisas do espírito que não projeta sombras, como a luz que se revela a si mesma, como a palma da mão que se abre e a si mesma se manifesta.

Meus caros amigos, ocultava-se um sentido subjacente e misterioso nos alicerces do velho convento franciscano que então se convertia em Casa do Direito. Sentido "poético", na acepção mais profunda deste termo, que significa instauração originária e fecunda, marcando a linha de nosso destino histórico, porque São Paulo, que nascera de uma Escola, iria ressurgir em virtude de outra Escola: a primeira fizera uma Província; a outra se destinava a fazer uma Nação!

Não julgueis que estou exagerando, ao dizer-vos que a esta Casa ficou intimamente vinculado o futuro da nacionalidade. Não preciso lembrar que a grande maioria dos Presidentes civis da República saiu dos bancos de nossa Academia. Nem evocar os grandes vultos da Jurisprudência, da Política, da Diplomacia, do Jornalismo, da Economia ou da Oratória, filhos desta Escola. Penso antes no bacharel anônimo que se esparramou pelo Brasil afora. Penso mais no advogado humilde que, de Vila em Vila, foi compondo o florilégio da consciência jurídica nacional, convertendo o sentimento do Direito 
numa das fontes de nossa consciência cívica, que brilha com esplendor insólito onde e quando violada.

Esta Faculdade nasceu, pois, para pulsar em uníssono com o coração de nossa Pátria. Todas as objeçōes, a que já aludi, e outras mais, como a dificuldade de se galgar a Serra do Mar para atingir-se o Planalto de Piratininga, todas elas vieram sendo superadas desde o primeiro ano, quando para São Paulo acorreram jovens de todas as províncias, de todas as categorias sociais.

Bastará dizer-vos que, logo com a primeira turma, a de 1828, se matriculava nas Arcadas um dos vultos mais altos da intelectualidade brasileira, Pimenta Bueno, Marquês de São Vicente, que Pontes de Miranda considera o maior de nossos juristas no século passado, ao lado de Teixeira de Freitas.

José Antonio Pimenta Bueno, filho de pais incógnitos, demonstra-nos que o elitismo não acompanhou o surgimento desta Faculdade, que se abria a todas as camadas sociais, em sentido profundo de igualdade e de compreensão humana.

Como contestar o acerto da localização dos Cursos Jurídicos em São Paulo, se um filho humilde da terra paulistana pôde receber ensinamentos que o tornaram um dos fundadores da Ciência Jurídica pátria, com obras que se espraiam desde o Processo Civil e Criminal ao Direito Internacional Privado, para culminar nas suas preciosas lições de Direito Constitucional, base imperecível de nosso literalismo político?

Três anos depois, chegava da Bahia, para ingressar nesta Escola, aquele que, sem sombra de dúvida, é a mais poderosa expressão do Direito Civil Brasileiro, - Teixeira de Freitas. Ele não era de origem humilde como Pimenta Bueno, más, um fidalgo de Cachoeira, filho dos Barões de Itaparica. O nobre e o plebeu unidos pela mesma destinação de implantar, cada qual no domínio jurídico de sua predileção, - um no Direito Privado, outro no Direito Público, - os alicerces da 
Jurisprudência nacional. Um paulista, o outro baiano; um filho do Sul, o outro do Norte, a demonstrar os bons auspícios que cercaram a instauração dos Cursos Jurídicos no Brasil, sob a égide de um grande Príncipe, cujo nome não poderíamos olvidar nesta noite de evocação e de justiça histórica.

Teixeira de Freitas, permaneceu pelo menos dois anos entre nós, terminando o seu curso no Recife. Começou, assim, uma tradição singular, na qual poder-se-ia vislumbrar um misterioso desígnio de constante intercâmbio de estudantes entre as duas Academias de Direito do País, como se a juventude espontaneamente sentisse a necessidade de ir tecendo, do Norte ao Sul, do Sul ao Norte, o tecido variegado da cultura brasileira.

Teixeira de Freitas foi o primeiro a vir do Recife para São Paulo, lá retornando para se diplomar. Depois dele quantos outros não repetiram essa mesma façanha nacional. Bastará recordar os nomes de Castro Alves, cujor estro é do Capibaribe e do Tietê; de Joaquim Nabuco, que harmoniza as duas latitudes em sentido de universalidade; e Rui Barbosa, cuja realização ciclópica no mundo da inteligência é tanto paulista quanto da Bahia e de Pernambuco.

Constituiram-se, desse modo, dois polos, em torno dos quais se traçou a elípse da cultura brasileira. Digo elípse da cultura brasileira e não apenas da cultura jurídica, porque, por uma predestinação histórica fundamental, enquanto que as áreas técnicas ou científico-naturais se distribuiram, desde o tempo de D. João VI, em vários institutos, como as Faculdades de Medicina da Bahia e do Rio Janeiro, as Academias Militares, as de Agricultura ou de Engenharia, toda a área humanística se concentrou, até bem poucos anos, nas duas Escolas de Direito.

Tal fato faz meu espírito remontar à época do Renascimento Italiano, quando todas as formas de saber se ordenavam epenas segundo duas esferas de conhecimentoo, que o 
humanista Marcílio Ficino, fiel às antigas tradições, denominava "Jurisprudentia ac Medicina".

$\mathrm{Na}$ linha do pensamento clássico, o termo "Jurisprudência" não se referia tão somente ao Direito, mas englobava todas as pesquisas sobre o homem, exigindo também atenção para as coisas divinas, consoante a lição esculpida no pórtico do Digesto: "divinarum atque humanarum rerum notitia: justi atque injusti scientia" Embora se possa considerar superada essa compreensão do problema, resta-nos sempre a lição de que o Direito, como dimensão radical do ser humano, não se reduz às suas expressões formais, mas, ao contrário, reclama um conteúdo de justiça inerente aos valores sociais.

Ainda não se fez um estudo profundo, como devera ser feito, sobre o que significou o fato de ter saído da Faculdade de Direito a grande maioria daqueles que se tornaram mentores da nacionalidade, pois, durante mais de um século, foram elas, repito, a morada inicial de poetas e romancistas, historiadores e diplomatas, economistas e sociólogos, psicólogos e políticos, jornalistas e historiadores.

Que significou a circunstância de se formarem em Escolas de Direito milhares de jovens que não iriam ser advogados, juízes, delegados ou promotores, mas exercer as mais diferentes atividades, nos domínios da indústria e do comércio, da política e das ciências sociais?

No se pode dizer que, no início de nossa formação cultural, como Nação independente, tenha sido um mal a concentração das atividades humanísticas nas Escolas de Jurisprudência. $\mathrm{Na}$ realidade, elaborava-se, sob a inspiração dos valores jurídicos, uma visão global de nós mesmos, correspondente a uma intuição sintética destinada a progressivas análises e desmembramentos.

E possível que a visão ordenada e sistemática do todo, inerente à experiência jurídica, tenha representado um bem, 
poupando-nos a distorção das especializações imaturas. Assim é que tivemos, de início, economistas dotados da compreensão unitária e global dos problemas sociais, sabendo distinguir entre Economia Política e Política Econômica, esta necessariamente interdisciplinar e sintética, utilizando-se da "ciência econômica" como instrumento básico para a compreensão e o desenvolvimento das "situações existenciais" que constituem o valor essencial de um povo.

Pelas mesmas razões, os "nossos" sociólogos, imbuídos do senso normativo do Direito, jamais se iludiram com o tratamento dos fatos humanos "como se fossem coisas", dispensando sempre a necessária atenção ao conteúdo axiológico da conduta humana e das estruturas comunitárias.

Tivemos, igualmente, políticos que souberam aliar o senso das oportunidades emergentes, em sua particularidade, com a independência dos planos de ação governamental, obedecendo a uma "dialética de funcionalidade", quase instintiva, entre meios adequados e fins concretos de agir. Políticos, em suma, que marcados pela virtude da prudência, souberam compreender a sedução, bem como os riscos do Poder, cientes e conscientes de que não há possibilidade de Política fecunda quando inexiste a composição harmônica entre o poder de agir e a responsabilidade jurídica que lhe corresponde.

Esse vivo sentimento de responsabilidade e concreção, esse sentido unitário e profundo da vida nacional, que o Direito propicia, pelo receio que seus cultores têm das soluções setorizadas e monocórdicas, explica a personalidade de um Prudente de Moraes, de um Campos Sales ou de um Rodrigues Alves. Sim meus amigos, o Direito é acima de tudlo, um empenho global de vida, porque é a vida mesma em todas as suas expressões, na medida em que todas devem se submeter às exigências éticas de uma convivência ordenada.

Nada de estranho, por conseguinte, que os maiores movimentos cívicos de nossa história, monárquica ou republica- 
na, tenham tido como principais personagens ex-alunos de São Paulo ou do Recife.

Épocas houve em que os estudantes formaram na vanguarda do processo histórico, porque eu vos digo que, às vezes, os mestres estão nas cátedras; outras vezes, estão nos pátios, abrindo o futuro pela voz da mocidade. Foi assim quando a juventude desfraldou a bandeira da emancipação dos escravos pela voz de Joaquim Nabuco e Castro Alves; de Tobias Barreto que ensinou, como estudante, aquilo que haveria de ensinar depois como mestre, instituindo a Escola do Recife.

Há, pois, uma continuidade fundamental entre a vida do estudante e a vida do mestre, revelando outra lição que não pode ficar esquecida: a da correlação ou complementaridade entre o pensamento e a ação.

Perdoai se vos lembro, neste instante, que, ao redigir, ainda nos bancos acadêmicos, o meu primieiro livro, O Estado Moderno, certo de estar interpretando a atitude espiritual de minha geração, manifestava o meu propósito de "teorizar a vida e viver a teoria na unidade indissolúvel do pensamento e da ação"

Sim, quem entra para esta Faculdade pode tornar-se poeta, político, historiador, diplomata, sociólogo ou jurista (porque nas Arcadas também se estuda Direito. ) mas há algo que é comum a todos, numa força unificante: é o sentido da concreção humana. Nossos poetas, por exemplo, jamais se isolam na torre de marfim de suas imagens, vaidosos de suas formas ou fórmulas esotéricas. Não há lugar nesta Casa para a poesia rebuscada que só se comunica de um cume de iniciados a outro, indiferentes à compreensão popular. A "nossa" poesia, a que nasce à luz ou à sombra das Arcadas, confunde-se espontânea e naturalmente com o falar da gente brasileira; é poesia que penetra, sem artifício, no coração do povo, tão imbuído está o poeta de seus sentimentos e aspirações. 
Vede como a Academia do Largo de São Francisco veio desfiando a sua história através do tempo, confundindo-se com a história do Brasil.

Não quero dizer-vos que tudo tenha sido rosas, que não tenha havido sombras e eclípses. Houve, fora de dúvidas, flexões e descaídas nas curvas existenciais das Arcadas, mas nunca nos faltou o senso de novas caminhadas, tal como se revela na carinhosa expressão a todo instante usada: "velha e sempre nova Academia" Faltar-nos-ia espírito crítico se ocultássemos as épocas incolores que atravessamos, em triste descompasso com as aspirações populares, ou com os progressos da ciência, mas o que nos tem valido, nestes cento e cinqüenta anos, é o sentido institucional da obra comum, a coragem de retomar a caminhada momentaneamente interrompida, ou comprometida, por termos olvidado, às vezes, que, acima de preferências ou impulsos afetivos, devem prevalecer os méritos intelectuais e éticos de mestres e alunos.

Crises e crises graves foram vencidas. Uma delas deu-se logo no início de nossa vida docente, quando um vazio deixou perplexos e preocupados os professores da época. $\mathrm{O}$ fato ocorreu em 1836, no mesmo ano em que Ramalho se tornava mestre nesta Academia, ao lado de Crispiniano: nesse ano apenas quatro estudantes requereram matrícula em nossa $\mathrm{Fa}$ culdade! Quatro estudantes apenas se apresentaram para o curso de Direito! Parecia que a Nação estava rejeitando a instalação dos cursos jurídicos em São Paulo, mas, logo no ano seguinte, o afluxo dos jovens às Arcadas demonstrou que se tratara de ocorrência fortuita.

Crises e descaídas, inevitáveis e incompreensíveis, pouco significam no sentido fundamental da existência de uma instituição como a nossa, cujo papel deve ser medido segundo suas linhas dominantes, e não por um ou outro fator negativo.

Mas, meus amigos, quero dizer-vos que assistia razão ao deputado José Custódio Dias, representante da Província de 
Minas Gerais, quando, na Câmara dos Deputados, apoiava a emenda de Nicolau Vergueiro e de Francisco de Paula Souza e Mello, que transferia para São Paulo o Curso Jurídico já destinado à cidade do Rio de Janeiro. Tinha razão o deputado mineiro, ao dizer (e eu vou ler suas palavras, para que não haja traição do pensamento) : "E $€$ preciso animar aqueles povos (os povios de São Paulo), de tantas vexações que tềm sofrido, e restaurar aquela Província da decadência a que a tem reduzido o continuado estado de opressão"

Eis aí uma verdade não raro esquecida: justificava-se a instalação dos cursos jurídicos na Província de São Paulo pela esperança de arrancá-la do torpor em que se encontrava, para que cessasse, em suma, a opressão psicológica e social em que vivia a gente bandeirante. Como vedes, a Faculdade de Direito surgia para mudar o estado de espírito "dos povos" de Piratininga. Não se podia prever que a mudança seria de maior alcance, alterando o panorama espiritual de São Paulo e do Brasil.

E que, trazida para São Paulo uma Escola, ela se convcrteu logo em Bandeira, em foco de bandeirismo. E, com efeito, necessário compreender que esta Escola cultiva o Direito e a Política em termos de Escola e em termos de Bandeira.

Que quero dizer com tais palavras? A Escola inicial, a Escola humilde de Anchieta, onde eram ensinados os curumins através da arte e da poesia, a Escola de Anchieta era uma projeção do Planalto, a falar para todo o Brasil. Depois, da cidade que nascera de uma Escola, projetou-se a audácia das Bandeiras. $\mathrm{O}$ bandeirismo foi um dar infinito e um pouco receber, o que explica a pobreza de São Paulo, em contraste com as riquezas daquelas paragens por onde ecoaram as pisadas dos desbravadores. Comparai a riqueza de Minas, de Ouro Preto e Sabará, Tiradentes e São João d'El Rei, com a penúria de São Paulo, onde mal podiam modestamente viver algu- 
mas dezenas de estudantes. Isso mostra que o bandeirismo redundou em ato coletivo de dedicação, o sonho e a cobiça das esmeraldas transformados no rude balisamento do território, "dobrando-as a linha das Tordesilhas".

Mas, na terceira década do século XVIII, o bandeirismo havia desaparecido, e a gente paulista, como já foi lembrado, sente-se oprimida. Nessa conjuntura, as Arcadas surgem como a bandeira imortal da cultura, dando início a uma tarefa de auto-consciência jurídica e auto-consciência histórica, a uma operação de desbravamento que jamais terminará.

150 anos, em qualquer país da América, já tem um profundo significado histórico, mas os nossos são 150 anos intensamente vividos, como aquele em que o destino reunia, numa única turma, a de 1870, figuras como as de Rui Barbosa, Castro Alves, Joaquim Nabuco, Afonso Pena e Rodrigues Alves, homens de todos os quadrantes e de todos os destinos.

O tempo vivido intensamente, é isto o que importa, meus caros amigos, estudantes do Largo São Francisco, porque o tempo, - já vos tenho dito e não será demais repetir, - o tempo, em si mesmo, nada é quando contado pelas batidas uniformes do relógio. O tempo nada é quando quantitativamente medido em termos de séculos, anos ou segundos. O que interessa é o tempo existencial, o que importa é o tempo vivido com a riqueza de nossas intencionalidades; o que se impõe e vale é o tempo de nossa dedicada participação, convertido em duração fecunda de vida; é o tempo que se incorpora à nossa personalidade e com ela se confunde. $€$ esse o tempo da Faculdade de Direito, que é tempo e templo da nacionalidade. 